\title{
NATURALEZA Y GEOGRAFIA EN EL PROCESSO DE FORMACIÓN TERRITORIAL COLOMBIANO
}

\author{
Gloria Maria Vargas
}

\begin{abstract}
Resumen: Las nociones sobre la naturaleza tuvieron una influencia destacada en la afirmación de los proyectos de consolidación territorial del naciente estado colombiano durante el siglo XIX. Las diferentes conceptuaciones a ella dadas, con sus imágenes, representaciones cartográficas e prácticas materiales derivadas, hicieron parte de los procesos de construcción social del territorio y legitimaron formas de poder que impactaron el proceso general de su formación. Estas conceptuaciones y prácticas materiales pueden considerarse también como partes remanentes del proyecto geopolítico colonial que permearon la "inteligentsia" criolla, quien a su vez asumió algunos de sus postulados selectivamente y los incorporó a su propio proyecto de poder. Parte de estos postulados se enmarca en una lógica dualista y excluyente, que con base en nociones deterministas de la naturaleza y de la geografía, construyó una ecuación de las relaciones naturaleza-sociedad que, en lugar de unificar el territorio con miras a un proyecto de nación, fomentó un patrón espacial segregador que persiste hasta hoy.
\end{abstract}

Palabras Clave: Territorio; Ideologías geográficas; Naturaleza; Colombia

\section{Introducción}

Este trabajo presenta algunas conexiones causales entre las nociones de naturaleza desarrollados a partir del conocimiento científico en los cortes de la ciencia occidental europea desarrollados en el territorio colonial de la Nueva Granada, a finales del siglo XVIII y comienzos de siglo XIX, la potencialidad territorial que estas nociones hicieron aflorar y las prácticas de poder que ellas desencadenaron en la elite ilustrada de la colonia y, posteriormente, en la naciente República.

Para ello, primero haremos una breve exposición sobre el contexto general de la ciencia en el periodo señalado, para después particularizar la situación de la misma en la península ibérica. Posteriormente mostraremos las relaciones entre conocimiento y gestión del territorio en el contexto referido, es decir, como la Corona Española emprendió un proyecto de investigación con el fin de extraer el valor de uso de las riquezas territoriales representadas en la naturaleza vegetal, principalmente, al igual que una exposición de lo que en este contexto significó la Expedición Botánica. Por último, nos detendremos en un análisis sobre lo que estas prácticas de conocimiento significaron para la dominación del territorio colonial y sobre el papel que la geografía cumplió en estos propósitos.

Las causalidades identificadas nos llevan a suponer que el conocimiento sobre la naturaleza y el territorio desarrollaron lo que llamamos de "ideologías geográficas" (MORAES, 1996) entendidas como valoraciones sujetivas del espacio, basadas en el reconocimiento de sus valores objetivos, sólo que convertidos en imágenes, representaciones, discursos, que desencadenan prácticas materiales.

El interés por estos temas nace de la poca reflexión que se ha dado alrededor del papel de la naturaleza en el proceso de formación territorial colombiano. Si bien es cierto que lo referente a los temas económicos, políticos y sociales de tal proceso han recibido atención por parte de historiadores y geógrafos (VARGAS, 1999), la forma como la naturaleza tropical y la singularidad regional del territorio colombiano interviene en los procesos de ocupación y posterior desarrollo del mismo, así como sus representaciones y lo que ellas significan colectivamente, no ha sido objeto de suficientes investigaciones. En general estos temas no se han tenido en cuenta como fuentes explicativas de los procesos de formación del territorio.

De otra parte, persiste en algunas disciplinas el temor al determinismo, que ahuyenta las posibles interpretaciones que incorporen los elementos naturales en los procesos sociales. En general, las ciencias sociales han sido refractarias al uso de la naturaleza como categoría explicativa en sus esquemas de interpretación, y desde la geografía misma se tiene un enorme recelo de caer en interpretaciones que puedan revivir antiguos determinismos.

Sin embargo, continuar ignorando el papel que la naturaleza y la geografía física jugaron en los procesos de formación territorial $y$, en particular, su papel en algunas 
coyunturas específicas, parece ser un sinsentido actualmente. La valoración del territorio y de sus riquezas naturales y la posibilidad de extraer de él sus valores de uso, fueron parte sustancial de los cálculos que la metrópoli española realizó para trazar sus políticas de gestión de los territorios coloniales, en particular el de la Nueva Granada. Por su parte, el creciente interés mostrado por la ciencia y los científicos europeos, en particular los naturalistas, en la descripción de esa naturaleza, lo que se comprueba con las Expediciones Botánicas realizadas en las colonias españolas, indica cómo la investigación sobre el territorio y su riqueza natural era una práctica común en la época. Esta práctica no se realiza apenas por interés estrictamente de la ciencia, sino que esta última se pone al servicio de los intereses comerciales de la Corona. Se pone de relieve entonces el vínculo entre naturaleza, conocimiento, y formas de dominación y explotación territorial.

Para dar un contexto al proceso territorial, es necesario resaltar que fue sólo en 1717 que el Nuevo Reino de Granada fue alzado a Virreinato, por el corto período de 6 años, es decir hasta 1723. Posteriormente y en 1739 el territorio del Virreinato incluía las actuales Colombia, Venezuela, Ecuador y Panamá, sólo que esta situación también sufrió un quiebre debido al centralismo de la Corona, que erigió a Gobernación el territorio de Venezuela, restableció la Presidencia de Quito y dejó como Virreinato del Nuevo Reino de Granada a Colombia y Panamá. (RESTREPO, 1991)

Estas readecuaciones mostraban las tensiones existentes entre la situación precaria que atravesaba la Corona y los intereses y alianzas regionales que ya comenzaban a ser manifiestas.

\section{La Ciencia europea en la transición del siglo XVIII al XIX}

Poco se habla sobre la ciencia y su desarrollo en los espacios ibéricos, asumiendo que la ciencia es un fenómeno principalmente de la Europa Central e del Norte o de la Europa anglo sajona. Sin embargo, en particular en el caso español, la ciencia tuvo una influencia grande en los proyectos de fijación del poder colonial en los territorios americanos y fue objeto de políticas directas que la Corona formuló e implementó para propiciar su desarrollo.

Tanto en Francia como en Inglaterra y en Alemania se cultivó durante mucho tiempo un desdén por la ciencia española, que se extendió a la cultura ibérica en general, y que atravesó el siglo XVIII, XIX y parte del XX en lo que algunos autores llaman de una filosofía protestante de la historia. La afirmación de Hegel de que "estando en España, ya se está en Africa", muestra muy bien esta postura (BAUER, 2002) que consideraba este continente menos evolucionado socialmente.

El historiador José Cañizares contesta esta visión y recrea la participación de España en la construcción de la modernidad. De igual forma, filósofos como DUSSEL (1995) y ZEA (1957) argumentan sobre el sesgo ideológico que considera la modernidad apenas como un fenómeno del norte europeo y van más allá argumentando que fue justamente el descubrimiento de América el que posibilitó la formación de una materialidad que originó la modernidad. De esta lectura emerge la constatación de los sesgos de la historiografía contemporánea que todavía hoy tratan a España y a la América Hispánica como externos a la historia de ese proceso (MIGNOLO, 1995).

Las áreas de desarrollo científico dadas por la Corona no fueron escogidas al azar, sino que tuvieron directa relación con la oferta natural encontrada en los territorios coloniales. En particular, la Nueva Granada con su exuberante pero temida naturaleza tropical, tuvo un papel muy importante que cumplir en la definición de los rumbos de la ciencia española.

Es necesario hacer una contextualización de estos eventos. La Corona española en el siglo XVII se había debilitado mucho como consecuencia de las guerras europeas, tanto dinásticas, como religiosas y comerciales. De igual forma, el territorio continental español había sufrido de epidemias, como las de Sevilla y Córdoba, en las que hubo entre 60.000 y 20.000 muertos. Había también problemas de manejo de los bienes de los diferentes Reyes, tanto por razones de inexperiencia e ineptitud, como de falta de coherencia en las políticas sectoriales de la Corona. En este sentido, es digno de mencionar que la expulsión de los moros y judíos trajo una enorme crisis agrícola que se expresó principalmente en Aragón y Valencia. La Corona se vio forzada a declararse en bancarrota varias veces, por lo que el siglo XVII puede considerarse una época de derrumbe del Imperio, aunque a comienzos del siglo XVIII fuera el más extenso imperio colonial del momento.

De otra parte, la crisis de la agricultura también se debía a la poca productividad de la tierra, concentrada en cabeza de la iglesia. Como la Corona tampoco disponía de una proto-industria, como sí sucedía en otros países europeos, el comercio se convirtió en su principal actividad económica y fuente de esperanzas para re- erguir el imperio.

Sólo que esta actividad también se veía amenazada por la expansión territorial de otras metrópolis, principalmente de los imperios británico y holandés, que afianzaban sus poderes en territorios africanos y asiáticos y se convertían en fuertes competidores comerciales en el circuito mercantil del Atlántico. 
Esta coyuntura especial hizo que se reconociera la necesidad de reorientar las políticas y las acciones de la Corona en los dominios coloniales, de forma que de estos territorios se extrajese la riqueza necesaria para equilibrar las finanzas.

Es bueno recordar que en Europa se daba un enorme realce de las ciencias debido a los descubrimientos de las leyes de la mecánica de Newton, el desarrollo del cálculo integral de Leibniz, la matemática, desde los desarrollos de Pascal, y, en general, una constatación de las posibilidades de dominio sobre naturaleza venida principalmente de los éxitos en los campos de la física y de la química. De igual forma, la conquista territorial de buena parte del planeta, el conocimiento de sus continentes y diversidad de paisajes, hizo aumentar la confianza en la capacidad de expansión del hombre sobre todos los hábitats y de su infinita posibilidad de dominio sobre los fenómenos naturales.

El reinado de Carlos III (1771-1792) fue fuertemente influenciado por las corrientes venidas de la ilustración francesa, que causaron grandes modificaciones en la gestión de los asuntos coloniales, en particular hacia su "modernización". Se explicitó la necesidad de una constatación más objetiva de las riquezas naturales de los territorios coloniales, que se complementara con medidas que permitieran convertir esta potencialidad en usos concretos que pudieran ser comercializados e inseridos en los circuitos mercantiles existentes.

Con este objetivo, se dieron las directrices de lo que serian los emprendimientos científicos de la Corona española en los territorios coloniales. Dada la oferta natural, la botánica, la geografía y la medicina fueron privilegiadas como áreas del conocimiento a ser incentivadas. Estas diferenciaciones disciplinares, sin embargo, no existían como tales en la época, ya que era común que aquellos formados en Medicina tuvieron amplios conocimientos botánicos, y estos en geografía, por lo que se les llamaba simplemente de naturalistas.

Las tres Expediciones Botánicas son prueba de la prioridad dada a estas áreas del conocimiento y fueron organizadas para el Virreinato del Perú y Chile, bajo la dirección de Hipólito Ruiz, la Nueva Granada, bajo la dirección de José Celestino Mutis, considerado uno de los mayores naturalistas españoles, y la Nueva España. Estos fueron los proyectos botánicos más ambiciosos y costosos realizados durante el reinado de Carlos III y durante toda la ilustración española, lo que muestra el apoyo que esta rama del conocimiento tuvo. Estas iniciativas requirieron de un enorme esfuerzo financiero y logístico que la Corona, que no sólo se dispuso a realizarlas, sino que colocó al servicio de las mismas a los científicos naturalistas mejor preparados, como al propio José Celestino Mutis. (NIETO, 2000)

No cabe duda que el interés en la botánica guardaba directa relación con la demanda por productos medicinales extraídos de las plantas. En cuanto a la división del trabajo científico, como ya fue dicho, la medicina y la botánica constituían un mismo campo, y era común que el médico fuera también conocedor de plantas, como era el caso del mayor taxonomista de la época y padre de esta ciencia, Carl Linneo ${ }^{1}$.

Para la Corona, la ecuación en verdad era muy simple: el conocimiento abriría las posibilidades de explotación de la riqueza natural y esta se revertiría en una mejora en las finanzas de la Corona, lo que a su vez fortalecería su dominio político sobre los territorios. Se reconocía que la extensión territorial de las colonias perdía valor si no era posible realizar la explotación económica de su riqueza natural. Al promover el estudio de la naturaleza, se promovía la expansión del comercio y la explotación sistemática de la periferia del Imperio.

Lo que debe ser recordado es que esto se daba en un marco de dominación política colonial y por lo tanto, el conocimiento, la historia natural, los saberes científicos, pertenecían a una misma estructura de poder y el conocimiento sobre los recursos naturales hacia parte de ese particular orden social. (NIETO, 2000).

$Y$ era bajo esa estructura de poder que se mantenían a los territorios coloniales como posesiones, lo que le daba derecho a la Corona de explotar sus recursos. Sólo que una eficaz explotación exigía un conocimiento mas preciso de sus elementos naturales de forma que pudieran ser incorporados en los circuitos mercantiles de la época y, con su valor de uso extraído, reforzarían el estado de dominación vigente.

\section{El desarrollo del conocimiento}

Según NIETO (2000), el desarrollo de la ciencia natural se hacía mediante la acumulación de conocimientos, que se llamaban de "descubrimientos". Sólo que el término "descubrir", que normalmente implica el conocimiento de un objeto antes inexistente, tenía otro significado. Se relacionaba con el proceso por el cual un objeto de la naturaleza entraba en los códigos del

\footnotetext{
${ }^{1}$ Muy consciente de las relaciones entre conocimiento y poder, Linneo, afirmaba que "Nuestro pobre conocimiento de la ciencia nos obliga a comprarle a extranjeros hierbas medicinales, té, quina, que anualmente nos cuesta una grandiosa cantidad de dinero... Sin ciencia nuestras sardinas serían pescadas por extranjeros, nuestras minas explotadas por extranjeros y nuestras bibliotecas invadidas por los trabajos de extranjeros." (NIETO, 2000: $51)$.
} 
lenguaje y de la nomenclatura desarrollados por la sistemática y la taxonomía de la ciencia natural de la época. El "descubrimiento" implicaba, por lo tanto, en hacer pasar el objeto natural por un proceso de construcción en el que se le atribuían características morfológicas y fisiológicas que se sumaban a su "estado de naturaleza" y que resultaban en la creación de un objeto científico.

Cada descubierta contribuyó al robustecimiento del sistema científico como un todo, tanto en términos cualitativos como cuantitativos, además de proporcionar honores a las instituciones, gobiernos, aristócratas y científicos involucrados ${ }^{2}$.

El proceso que incorporaba los objetos de la naturaleza en los códigos y lenguaje de la ciencia europea se constituía en una forma de apropiación de esa naturaleza, como un estado posterior a la apropiación que se hacía del territorio. Esta última se realizaba apenas con la proclamación del mismo en nombre del Rey y con su inserción en la normatividad de la Corona, lo que por su vez abría las puertas a la dominación política de las poblaciones en él presentes.

Ya la apropiación de la naturaleza implicaba una racionalización de todo el proceso de "descubierta", que era dividido en etapas y a las cuales se les atribuían una serie procedimientos y técnicas científicas. A este respecto, NIETO (2000) identifica 5 etapas: una primera en la que el espécimen era nombrado o bautizado, según los cánones taxonómicos, proceso que se realizaba en latín. Una segunda en la que el espécimen era representado mediante dibujos, en general realizados por ilustradores y artistas, que se encargaban de estetizar el objeto. Una tercera etapa que consistía en hacer una descripción de la planta según los cánones botánicos; una cuarta que se proponía organizar y exponer las virtudes de la planta, según las demandas de las enfermedades europeas de la época. Y por último, la extracción de la parte o principio activo que sería la base para la fabricación de los producto medicinales comercializables.

Nombrar científicamente los objetos naturales era el primer paso en el proceso de su apropiación, ya que así se les daba una identidad como objetos científicos, de esta forma dejando atrás su contenido natural. Por intermedio de la taxonomía, se realizaban los inventarios que hacían posible la acumulación de información y su posterior ordenamiento en los centros de investigación de la metrópoli. Al incorporar los objetos naturales en esta sistematización taxonómica, no sólo se incorporaban a un sistema de denominación, sino que por su intermedio se realizaba la domesticación de la naturaleza in situ, es decir se colocaba "el (des)orden natural" bajo el orden conocido y manipulable de la sistematización, sin lo cual la naturaleza sería siempre vista como una naturaleza amenazadora y caótica. El conocimiento científico, principalmente la taxonomía, impuso un orden al supuesto caos que significaba la diversidad de la naturaleza tropical.

La variedad y complejidad de la naturaleza de los territorios tropicales era homogenizada con las técnicas naturalistas, que desarraigaban los objetos naturales de sus medios y los incorporaban en los sistemas de transporte, clasificación, representación y documentación desarrollados por la ciencia. Los ilustradores, por su vez, tenían un papel muy importante, ya que los dibujos por ellos realizados simplificaban la complejidad de la naturaleza, haciéndola mas dócil e inteligible a los investigadores.

Al ser colocados en los herbarios, las colecciones, los museos naturales, etc., estos objetos se legitimaban, ya no como naturales, sino como objetos científicos o de conocimiento. A pesar de no ser reconocido el conocimiento que sobre las plantas y sus usos se tenía en los territorios de origen por los pueblos indígenas en estos procesos de legitimación del saber, estos habían sido utilizados, como lo afirmó el historiador Florentino Vezga. En el siglo XIX, este historiador naturalista trazó un programa de investigación para la Sociedad de Naturalistas Neogranadinos, con el fin de recuperar la tradición de estos conocimientos y dar continuidad al estudio de la ciencia en la Nueva Granada, en particular, a los conocimientos botánicos comenzados en la Expedición Botánica (OBREGÓN, 1991.)

La explotación botánica hizo parte así de una reordenación del mundo que se basó en los códigos desarrollados por la cultura científica. Este orden creado en el mundo natural con la taxonomía y la sistemática, no puede separarse del control que sobre la naturaleza se ejerció con estos instrumentos ni de la importancia que fue adquiriendo la cultura científica como instrumento de dominación.

La eficacia de la taxonomía está en que creó un espacio coherente y ordenado de significados, sólo que por fuera de este orden creado continuó existiendo una realidad considerada caótica y compleja. La taxonomía se convirtió así en un orden en oposición a las cosas en si mismas, al desorden natural de la naturaleza, que, al ser incluida en un sistema de conocimiento, prescindió de su condición de natural y se convirtió en una naturaleza científica 0 , simplemente, en conocimiento.

2 La ciencia recibía apoyo de mecenas privados, en general aristócratas que financiaban a científicos determinados y cuyos hallazgos podían terminar por lo tanto, en sus colecciones particulares. 
Posterior a su inserción en el lenguaje científico, estos objetos "cientifizados" eran exhibidos en espacios de visibilidad y colocados como representantes de sus lugares de origen, que así eran también incluidos en el sistema de conocimiento. Se realizaba así la inclusión de los espacios coloniales en los espacios ordenados de la ciencia y la absorción de los objetos naturales en el espacio "civilizado" europeo, de la normalización y del conocimiento. El aparente orden de estas exhibiciones y de todas estas prácticas se distanciaba de la violencia inherente al proceso de apropiación de los territorios y de remoción de su naturaleza.

\section{El papel de la Geografía}

El desarrollo de la geografía en Colombia, o de un pensamiento geográfico, muestra algunas particularidades y constantes. Una de ellas es la restricción en que se mantuvo este conocimiento, limitado a determinados círculos. Esto influyó en su falta de desarrollo como una actividad universal, tanto en su enseñanza, como en su práctica profesional. Como muestra MONTAÑEZ (1999), no sólo existía una especie de cofradía de la geografía, sino que las personas e instituciones que la ejercían tenían vínculos estrechos con los gobiernos. El autor afirma que esto puede ser un indicio de la posición de la geografía como un conocimiento al servicio del Estado y de cómo este determinaba hasta donde su contenido podía ser o no divulgado y compartido.

Según la periodización del pensamiento geográfico realizada en el texto citado, hasta 1871 se puede considerar el periodo de la colonia, y de 1871 a 1931, el de la independencia. Estos son los dos períodos que nos interesan, ya que en ellos surgieron las ideas y se realizaron las acciones sobre el territorio que llevaron a la emancipación de la Corona.

Como este autor comenta, el contexto histórico de los diferentes períodos marca el carácter e impacto del pensamiento geográfico correspondiente. En este sentido, la geografía de la colonia fue en gran medida realizada a través de crónicas dêscriptivas realizadas por los exploradores y conquistadores. Se puede decir que esta geografía descriptiva tenía el mérito y función de hacer visibles las riquezas y características de los territorios, información que le era muy valiosa a la Corona. Algunos de estos cronistas fueron Fernández de Oviedo, Cieza de León, Jiménez de Quesada, y Juan de Castellanos, todos del siglo XVI.

Todas estas crónicas eran celosamente controladas por la Corona, que consideraba estos saberes estratégicos y por eso, restringía su divulgación y uso. Lo estratégico del conocimiento sobre el territorio se deja entrever en la creación, por parte de la Corona, del cargo de cosmógrafo, una especie de cronista encargado de hacer la descripción geográfica del territorio, aprovechando el conocimiento que sobre el mismo tenían los funcionarios coloniales y teniendo en cuenta los hallazgos realizados en las diferentes administraciones. Las obras descriptivas continuaron siendo elaboradas durante el siglo XVII con la misma intención y objetivo de tener un inventario de los territorios (MONTAÑEZ, 1999).

Ya el período de la independencia, marcado por MONTAÑEZ (1999) como siendo desde la revolución Comunera, coincide justamente con la realización de la Expedición Botánica, y la Expedición Hidalgo, ambas patrocinadas por la Corona, además de la expedición de Humboldt, patrocinada por él mismo. La primera de estas, que se inició en 1783 , se extendió hasta 1810. La segunda, se realizó hasta 1807 y realizó una extensa descripción y levantamiento cartográfico de la costa norte de América del Sur.

El gran científico Francisco José de Caldas reconoció siempre la importancia de la geografía y su relación con la política, como lo expresa en la siguiente cita:

Si se formase una expedición geográfica 0 económica destinada a recorrer el Virreinato; si esta se compusiese de un astrónomo, de un botánico, de un mineralogista, de un encargado de la parte zoológica y de un economista, con dos 0 , mas diseñadores... no hay duda de que dentro de pocos años tendríamos la gloria de poseer una obra maestra en la geografía y en la políica, y de haber puesto los fundamentos de nuestra propia prosperidad. (MONTAÑEZ, 1999 : 9).

No nos detendremos a analizar la obra de Humboldt, en particular su Viaje a las Regiones Equinocciales del Nuevo Continente, realizado entre 1799 y 1804, por creer que se sale de los objetivos de este trabajo. Como naturalista, no estaba al servicio de la Corona ni era mestizo y, por lo tanto, no representa los grupos científicos de interés de este trabajo. Además, como lo explica MONTAÑEZ (1999), existió una barrera idiomática con su obra, escrita en alemán, que no fue conocida por la elite ilustrada criolla sino hasta mediados del siglo XIX. Por lo tanto, no tenemos como suponer que influenció la formación de las ideologías geográficas en el periodo que nos interesa.

La geografía, como puede verse, tuvo un papel fundamental en la instrumentación de todo el régimen colonial. La empresa colonial creó lo que GREGORY (1999) llama de "geografías duales", es decir, espacios de subordinación contenidos dentro de 
un espacio global, ordenado y organizado según un particular sistema de conocimiento.

Estas geografías duales originaron categorías dicotómicas como metrópoli-colonia, centro-periferia, es decir, diferenciaciones espaciales que también crearon paisajes simbólicos en los cuales las colonias eran representadas justamente por todo aquello que no compartían con el centro civilizado: sus atributos naturales. En este sentido, la producción de estos espacios se dio según una lógica y un sistema de diferencias, de un orden conceptual que absolutizó a Europa elevándola a referente geográfico, natural e cultural. En este sistema, las colonias fueron definidas por sus negatividades, por todo aquello que las hacia diferentes y distantes del referente europeo, que las afirmaba como pertenecientes a un orden natural, fuera de la historia y de la civilización. Si el referente era Europa, sus prácticas de dominación y de explotación pasaron a ser naturalizadas, pues hacían parte de un estado de cosas o status quo normal y deseable.

Puede decirse que la geografía contribuyó de diferentes maneras al proyecto colonial: ayudó a organizar el aparato administrativo colonial, realizó los inventarios territoriales y de recursos, describió los territorios, hizo el levantamiento de los mapas y ayudó a planear las estrategias militares. Pero también participó en un nivel conceptual, ya que ayudó a crear un orden que implicaba la absolutización del espacio europeo y su consolidación como referente universal. Ayudó también a crear las categorías binarias que reforzaban y legitimaban el poder de los espacios dominadores y la subordinación de las colonias.

\section{Los fenómenos emergentes}

Tanto la Expedición Botánica como los otros proyectos que realizaron levantamientos e inventarios de la naturaleza en los territorios coloniales, fueron realizados por naturalistas europeos y criollos. En las colonias se había gestado una elite ilustrada compuesta por los hijos de españoles nacidos en América, que por su ascendencia europea, había tenido acceso a una educación universitaria, en ocasiones en los centros académicos europeos. A los representantes de esta elite se les llamó de criollos.

Entre ellos se encontraba Francisco José de Caldas, apellidado del Sabio Caldas, que sería el primer director del Observatorio astronómico de Bogotáa, Jorge Tadeo Lozano, Francisco Antonio Zea, Sinforoso Mutis, Rixo y Carbonel. Muchos de ellos participaban en las llamadas Sociedades de Amigos del
País, creadas en la Nueva Granada con la finalidad de promover el bien de la comunidad y fomentar algunas actividades económicas como la agricultura, industria e comercio. Pero también servían de espacio de discusión donde se comentaba la situación del virreinato y donde eran debatidas las ideas políticas y propuestas de acción, en particular, aquellas que tenían relación con la gesta independentista (OBREGÓN, 1991)

A la par de la efervescencia política promovida desde los círculos de esta "inteligentsia", se daban los estímulos que el conocimiento sobre el territorio iba gestando. La constante investigación tanto geográfica como botánica fue dando un contenido diferente al territorio, contenido que comprobaría la singularidad del mismo. Esta singularidad natural y territorial, además del potencial de explotación económica que prometía, alimentó un ansia que precisaba de acciones en la esfera política. Además, la singularidad territorial alimentó la construcción de una identidad cimentada en lo que el futuro emancipado podría traer. De esta forma, el conocimiento sobre el territorio y sus representaciones se convirtieron en ideologías geográficas que alimentaron una identidad territorial, que tuvo influencia en el proyecto político de emancipación de la Corona.

Es decir, el espacio construido a partir de los contenidos nuevos dados al territorio, productos del conocimiento de su riqueza natural y de sus potencialidades comerciales, permitieron la consolidación de una identidad territorial y la elaboración de una ideología que influenciaron los contenidos políticos e que irían a subsidiar las acciones de independencia de la Corona española.

Lo paradójico de esta situación es que estas representaciones territoriales que influenciaron las prácticas políticas de esta elite continuaban fuertemente influenciadas por las visiones europeas y, en ese sentido, continuaban teniendo un contenido dicotómico y dualista.

Es así que a partir de las ideas de independencia y de las prácticas y acciones que de ellas se derivaron, fueron construidas, de nuevo, geografias duales, sólo que ahora en un nuevo espacio político, el del Estado colombiano naciente. El espacio que se desarrolla mantiene su carácter excluyente y dualista, en el cual la región andina se erige como centro, rodeado de espacios periféricos como la Orinoquia, la Amazonia y la región Pacífica, que se subordinan a su lógica. Este rasgo territorial no ha sido superado en el curso de los anõs, siendo origen y causa de los desequilibrios socio-espaciales que Colombia enfrenta hoy y que, sin la debida importancia a él dado, difícilmente será superado.

${ }^{3}$ El observatorio Astronómico de Bogotá fue inaugurado en 1805 y fue el primero en su género en América Latina. 
VARGAS, G. M. (2006). Nature and Geography in the Colombian Territorial Formation. Revista do Departamento de Geografia, n. 18, p. 9-15.

Abstract: The notions on nature had an important influence on the territorial consolidation of the early Colombian State during the XIX century. Different notions of nature, with its cartographic representations and material practices, were part of the social construction of the territory and gave legitimacy to power structures that impacted the whole process. These notions and material practices can also be seen as part of the colonial geopolitical project that permeated the "intelligentsia criolla", which incorporated some of its postulates selectively for its own power project. Some of these postulates are framed in a dualistic and excluding logic based on deterministic notions of nature and geography, and built nature-society equations that instead of unifying the territory as a step in the nation building, fomented a segregated spatial pattern that persists until today.

Keywords: Territory, Geographic Ideologies, Nature, Colombia.

Recebido em 21 de junho de 2005, aceito em 2 de outubro de 2005.

\section{Referências}

BAUER, R. (2002) The postcolonial origins of Modernity. William and Mary Quaterly.vol. LVIX, No. 4.

CAÑIZARES, J. (2001) How to write the History of the New World. Histories, Epistemologies and Identities in the EighteenthCentury Atlantic World. Stanford, Stanford University Press.

DUSSEL, E. (1995) The invention of the Americas. Eclipse of "the other" and the Myth of Modernity. New York, Continuum.

GREGORY, D. (1999) Colonizing Geographies .Oxford, Blackwell.

MIGNOLO, W. (1995). The Darker Side of Renaissance: Literacy, territoriality and Colonization. Ann Arbour, Ann Arbour.

MONTAÑEZ, G. (1999) Elementos de Historiografía de la Geografía colombiana. Revista de Estudios Sociales, No. 3, junio.

MORAES, A. C. R. (1999) Ideologías Geograficas. $3^{a}$ Edición. São Paulo, Hucitec. 1996.

NIETO OLARTE, M. (2000) Remedios para el Imperio. Historia Natural y La apropiación del Nuevo Mundo. Bogotá, Instituto
Colombiano de Antropología e Historia - ICANH. . 279 p.

OBREGÓN, D. (1991). La Sociedad de Naturalistas Neogranadinos y la Tradición Científica. Anuario Colombiano de Historia Social y de la Cultura. vol 18-19.

PALACIO, G. (ed). (2001) Naturaleza en disputa. Ensayos de Historia ambiental de Colombia. Bogotá, Universidad Nacional de Colombia; Instituto Colombiano de Antropología e Historia - ICANH.. 480 p.

RESTREPO FORERO, O. (1991) El papel de saber en el Nuevo Reino. Anuario Colombiano de Historia Social y de la Cultura. Vol. 18-19.

VARGAS, G. M. (1999) Território e poder: a formação sócio-espacial colombiana. São Paulo, 1. v. Tese (Doutorado). Faculdade de Filosofia, Letras e Ciências Humanas, Universidade de São Paulo.

ZEA, L. (1957) América en la Historia. Ciudad de México, Fondo de Cultura Económica. 